\title{
The Impact of Atmospheric Phenomena on South Korean Students' Engagement at School through the Mediating Effect of the Students' Health
}

\author{
Shelley Choi \\ Yongsan International School of Seoul, Seoul, South Korea \\ Email: 19.shelley.choi@yisseoul.org
}

How to cite this paper: Choi, S. (2018) The Impact of Atmospheric Phenomena on South Korean Students' Engagement at School through the Mediating Effect of the Students' Health. Atmospheric and Climate Sciences, 8, 307-317.

https://doi.org/10.4236/acs.2018.83020

Received: April 5, 2018

Accepted: May 21, 2018

Published: May 24, 2018

Copyright $\odot 2018$ by author and Scientific Research Publishing Inc. This work is licensed under the Creative Commons Attribution International License (CC BY 4.0).

http://creativecommons.org/licenses/by/4.0/

\begin{abstract}
This study examined how South Korea's regular significant atmospheric phenomena, the yellow dust and the monsoon, affected students' health and academic engagement at school. Five hundred middle and high school students were surveyed to figure out the atmospheric impacts on the students' lives. The results of this study found that the severity of yellow dust and monsoon conditions experienced by the students negatively influenced their academic engagement. However, the variable of students' concerns about their health was shown to have a mediating effect between the intensity of yellow dust and the level of academic engagement. These results indicated the need to alleviate the yellow dust and monsoon atmospheric phenomena and their effects at both the school and national levels in order to improve the academic engagement of students in South Korea.
\end{abstract}

\section{Keywords}

Atmospheric Conditions, Yellow Dust, Monsoon, Students' Health, Academic Engagement, South Korea

\section{Introduction}

Over the last few decades, climate change has significantly increased average global temperatures, damaged forests and marine life, and reduced air quality. The main types of air pollution, namely smog, acid rain, and ozone depletion, have hindered people's ability to conduct their daily lives and been a source of increased mortality. Air pollution was named as the fourth leading risk factor for 
premature death around the world. Studies have reported that approximately 5.5 million deaths occurred due to diseases associated with air pollution in 2013. In the United States alone, air pollution has contributed to nearly 200,000 deaths, largely caused by asthma, bronchitis, and heart disease [1]. Air pollution is also economically detrimental. In 2016, it cost the global economy about 225 billion USD in lost labor income [2].

Similar to many other residents living in major cities who are exposed to particulates in the air from various sources, urbanites in South Korea encounter air pollution such as vehicle exhaust fumes every day. However, regardless of whether they reside in urban or rural areas, Koreans face substantially reduced air quality due to the yellow dust from Mongolian deserts every spring. Along with this yellow dust, pollution from China is also added, thereby making Korea's air quality definitively worse. When special alerts are given on particularly polluted days, half of all vehicles are banned from operating on public roads and all government buildings' parking lots in Seoul are shut down to discourage workers from using their cars. The elderly, children, and patients with respiratory illnesses are advised to remain indoors for the duration of the alert [3] [4]. In addition to the dust and pollution, Koreans are confronted with a heavy rainy season every summer, a weather phenomenon known as the monsoon. The monsoon can inflict massive casualties, leave thousands of people homeless, destroy industrial capacity, and cause severe transportation delays [5].

In order to address the consequences of these atmospheric phenomena, the scientific community in South Korea has recently begun taking a greater interest in the ways that atmospheric phenomena impact people's lives. In the past, research simply focused on the loss of life and damage to the agriculture, fisheries, and manufacturing industries caused by atmospheric phenomena, overlooking their effects on people's daily lives [6] [7] [8] [9]. Most importantly, no study has been conducted regarding the effects on students' lives at school, even though middle and high school students are more impacted by atmospheric conditions than any other demographic group as their physical education classes and recesses are conducted differently based on the day's atmospheric conditions. Do students feel bothered by adverse atmospheric conditions, such as blankets of yellow dust and heavy rainfall, when studying? Are their mental and physical health negatively affected by these severe atmospheric conditions? This study was designed to explore whether the yellow dust and monsoon affect students' engagement in their studies through the mediating variable of their health. The outcomes of this study will be helpful for determining whether there are negative effects on students' academic engagement at school and, if so, what sort of institutional and policy changes should be made to mitigate them.

\section{Impacts of the Atmosphere: Jangma and Hwangsa}

South Korea has four distinct seasons, each of which has a different amount of precipitation. Annual precipitation ranges from $1000 \mathrm{~mm}$ to $1800 \mathrm{~mm}$, but more than half of it falls during the monsoon season, called jangma, during which a 
stationary monsoon front lingers across the Korean peninsula for about a month in summer from late June to mid-July [10]. Monsoons occur when the moist air over the Pacific meets the cooler continental air mass [11]. Heavy rainfall during the jangma season causes floods and landslides, destroys homes, kills people, and generates significant economic loss. In addition, diseases like cholera run rampant in flooded areas. During the monsoon season in 1987, 167 people lost their lives and 512 more died as a result of the Thelma typhoon that struck during the monsoon period [12]. In 2001, the jangma was causing rain at a rate of $100 \mathrm{~mm}$ per hour and killed 54 people in the Seoul metropolitan area and flooded 21,144 houses, leaving more than 40,000 people homeless [13]. Although South Korea has developed flood control systems to prevent overall flooding, sudden local torrential rainfall can cause a significant amount of death and destruction.

Although the Korean climate has relatively stable levels of precipitation during the fall and winter, each spring yellow dust known as hwangsa blows over the country. The yellow dust has blown into Korea from the dry Mongolian desert for a long time. The hwangsa brings particles that are mostly between 1 and $10 \mu \mathrm{m}$. It also carries various minerals, such as aluminum, calcium, potassium, and silicon, from Chinese industrial areas. Yellow dust has been blowing in more frequently and has become more harmful than ever before to the point that, on March 21, 2017, Seoul had the worst air quality in the world, second only to New Delhi [14]. The hwangsa can irritate the soft tissues in the eyes, nose, mouth, and throat, and provoke respiratory and cardiovascular problems due to its high concentration of minerals and other pollutants [15]. It can also damage sensitive equipment, such as computers, and stop production in factories. For instance, it increases the number of defects in silicon wafers produced for use in semiconductor chips and causes painting in automobile factories to stop due to concerns about dust particles getting into the paint. On days when the concentration of particulates is particularly high, hundreds of flights are suspended and approximately $30 \%$ of construction workers face lost wages because most construction must stop. The hwangsa also blocks sunlight, hindering the growth of crops [16].

Beyond macro-level effects, atmospheric conditions have strong effects on individuals' health and lifestyles. Students who spend most of their time participating in various indoor and outdoor activities are also vulnerable to undesirable atmospheric conditions. However, non-empirical research has been conducted on the impact of atmospheric conditions on South Korean students. This study attempted to fill this gap by examining the influence of the yellow dust in spring and the heavy monsoon rains in summer on middle- and high-school students' health and academic engagement. This study would therefore provide basic data to determine whether institutional and policy changes should be made to improve students' engagement at school.

\section{Methods}

Atmospheric conditions are expected to influence both students' health and 
academic engagement at school. Thus, the current study examined how the yellow dust and monsoon affected students' engagement as mediated by the effects on their health. The study was structured according to the following hypotheses:

Hypothesis 1: The intensity of air pollution caused by yellow dust and amount of rain caused by the monsoon would negatively affect middle and high school students' academic engagement.

Hypothesis 2: Middle and high school students' health would be a mediating factor between atmospheric conditions and the students' academic engagement at school.

The independent variables in this study were the student experience of the intensity of yellow dust in the spring and the amount of rainfall in the summer for a given year. The respondents were asked with a single-item question, "How seriously have you recently experienced the yellow dust during the last spring (or the monsoon during the last summer)?" They also had to respond by choosing one option from a 5-point Likert scale where 1 corresponded to "not a problem at all" and 5 corresponded to "a very serious problem" such that higher scores indicated greater severity of the relevant atmospheric condition.

The dependent variable for this study was students' academic engagement at school as measured by responses to Choo and Sohn's Korean version of the Utrecht Work Engagement Scale-Student (UWES-S) [17] [18]. The UWES-S consisted of 17 items scored on 7-point Likert scale with higher scores where 0 corresponded to "never" and 6 corresponded to "always" such that higher scores indicated greater frequency. The scale's Cronbach's Alpha was 0.953 in this study, indicating that it had high reliability and internal consistency.

Student health, which consists of both physical and mental health, was the mediating factor between atmospheric conditions and academic engagement at school. Physical health was measured by responses to the Korean version of the Whiteley Index (WI) developed by Shin and Won [19], which has been widely used to assess concerns or beliefs about physical illness. Responses to the WI questions could be given on a 5-point Likert scale where 1 corresponded to "not at all" and 5 corresponded to "a great deal" such that higher scores indicated that the respondent was more anxious about their physical health. The scale's Cronbach's Alpha was 0.822. Mental health was measured by responses to Park and Seo's Korean version of the Perceived Stress Scale (PSS) scale developed by Cohen, Kamarck, and Mermelstein [20] [21]. The PSS has been commonly used to measure perceived stress in various cultures. Responses to the PSS questions could be given on a 5 -point Likert scale where 0 corresponded to "never" and 4 corresponded to "very often" such that higher scores indicated that the respondent experienced stress due to the event in question more frequently. The scale's Cronbach's Alpha was 0.933.

This study controlled for the effects of communication between parents and children on academic engagement because previous studies have shown that communication between parents and children affects behaviors at school [22] 
[23] [24]. Kim's Korean version of Parent-Adolescent Communication (PAC) survey originally developed by Barners and Olson was used to determine the quality of the communication between parents and children [25] [26]. The respondents were asked how accurately each statement described their relationships with their parents where a 0 corresponded to "not at all" and a 4 corresponded to "very well" such that higher scores indicated that the statement more accurately described their essence of communication. The first 10 items were related to the degree to which communication was open and the other 10 items were related to problems in communication. The Cronbach's Alpha for the openness part of the survey was 0.936 and the Cronbach's Alpha for the problematic communication part of the survey was 0.934 . SPSS Statistics v. 25 was used to conduct the statistical analyses.

In terms of sampling, this study's subjects came from one middle school for girls and one high school for girls, both of which were located in Seoul, South Korea, that allowed for the conduct of surveys on their students. Based on the practice followed in other studies, a preliminary questionnaire was designed for a pilot study which was conducted in July, 2017. The main questionnaire was then revised based on the findings of the pilot study. A total of 500 students, 300 of which were from the middle school and 200 of which were from the high school, were randomly selected by a random number generator, and the official survey was conducted in August, 2017. Of the 351 questionnaires that were returned, which indicates a return rate of $70.2 \%, 345$ valid questionnaires were applied for the final analysis.

\section{Results}

The subjects for the study were 13 to 16 years old $(\mathrm{M}=14.59, \mathrm{SD}=1.12)$. More than two-thirds of them were reported to be middle school students $(72.3 \%)$ : $19.8 \%$ were in their first year of middle school, $29.7 \%$ were in their second year of middle school, $22.7 \%$ were in their third year of middle school, and $27.7 \%$ were in their first year of high school. In terms of gender, the respondents consisted of females only because the selected schools were girls' schools.

The survey results showed that $78.9 \%$ of the respondents reported experiencing serious atmospheric conditions in the previous year. The mean score of the question asking students about the seriousness of yellow dust that they had experienced during the preceding spring was 4.2 out of 5 and $79.1 \%$ of the subjects described the yellow dust as "a slightly serious problem" or "a very serious problem". The mean score of the question asking students about the volume of rain that they had experienced during the preceding summer was 4.26 out of 5 and $78.8 \%$ of the subjects described the volume of rain as "a slightly serious problem" or "a very serious problem".

As for the correlations among the variables, significant positive correlations emerged between yellow dust intensity and amount of rainfall $(\mathrm{r}=0.173, \mathrm{p}<$ $0.01)$, yellow dust and students' concerns about their health $(r=0.110, p<0.05)$, students' concerns about their health and problematic communication with 
parents $(\mathrm{r}=0.221, \mathrm{p}<0.01)$, and open communication with parents and academic engagement at school $(r=0.204, p<0.01)$. However, other correlations, such as those between monsoon and academic engagement $(r=-0.116, p<$ $0.05)$, students' concerns about their health and academic engagement $(r=$ $-0.297, \mathrm{p}<0.01)$, students' concerns about their health and open communication $(\mathrm{r}=-0.128, \mathrm{p}<0.05)$, open communication and problematic communication $(\mathrm{r}=-0.638, \mathrm{p}<0.01)$, and problematic communication and academic engagement $(\mathrm{r}=-0.121, \mathrm{p}<0.05)$ were negatively correlated. The correlation between open communication and problematic communication were relatively high because they were sub-variables of the same variable. The overall results of the analysis are given in Table 1.

Meanwhile, the maximum $r$-value found in this analysis was 0.638 , the maximum Variance Inflation Factor (VIF) was less than 2.014, and the minimum tolerance among the variables was 0.537 . Multicollinearity may be problematic when the correlation coefficients are greater than or equal to 0.7 , the VIF values are greater than 10, or tolerance values are less than 0.1 [27], but based on the results of this study, multicollinearity was not problematic.

In order to examine whether the data supported the hypotheses, Baron and Kenny's four-step procedures were used to determine statistical significance: 1) between the independent variable and the dependent variable, 2) between the independent variable and the mediator variable, 3) between the mediator and the dependent variable, and 4) between the independent and the dependent variable while controlling for the mediator variable. If the results of the last analysis result in a statistically insignificant relationship between the original independent and dependent variables, there is full mediation. If it only reduces the statistical significance of the relationship, not completely blocking, then there is partial mediation [28].

According to this procedure, the statistical significance of the relationships between student perceptions of both yellow dust and amount of rainfall,

Table 1. Means, standard deviations, and correlations among the variables.

\begin{tabular}{|c|c|c|c|c|c|c|c|c|}
\hline Variable & Mean & SD & 1 & 2 & 3 & 4 & 5 & 6 \\
\hline 1) Academic engagement & 1.934 & 0.247 & 1 & -0.078 & $-0.116^{*}$ & $-0.297^{\star *}$ & $0.204^{\star *}$ & $-0.121^{\star}$ \\
\hline 2) Yellow dust intensity & 4.200 & 0.791 & -0.078 & 1 & $0.173^{\star *}$ & $0.110^{*}$ & -0.029 & 0.046 \\
\hline $\begin{array}{l}\text { 3) Amount of rainfall } \\
\text { (monsoon) }\end{array}$ & 4.260 & 0.932 & $-0.116^{*}$ & $0.173^{\star \star}$ & 1 & 0.037 & -0.018 & 0.074 \\
\hline $\begin{array}{l}\text { 4) Students' concerns } \\
\text { about their health }\end{array}$ & 1.123 & 0.412 & $-0.297^{\star *}$ & $0.110^{*}$ & 0.037 & 1 & $-0.128^{*}$ & $0.221^{\star *}$ \\
\hline $\begin{array}{l}\text { 5) Parents-students: } \\
\text { Open comm. }\end{array}$ & 2.930 & 0.235 & $0.204^{* *}$ & -0.029 & -0.018 & $-0.128^{*}$ & 1 & $-0.638^{\star *}$ \\
\hline $\begin{array}{l}\text { 6) Parents-students: } \\
\text { Problematic comm. }\end{array}$ & 1.905 & 0.265 & $-0.121^{\star}$ & 0.046 & 0.074 & $0.221^{\star *}$ & $-0.638^{\star *}$ & 1 \\
\hline
\end{tabular}

Note: $\mathrm{SD}=\sqrt{\sum_{i=1}^{n}\left(y_{i}-\bar{y}\right)^{2} / n-1} \cdot{ }^{\star}$ Correlation is significant at the 0.05 level (2-tailed); ${ }^{*}$ Correlation is significant at the 0.01 level (2-tailed). 
academic engagement at school, and students' concerns about their health were measured. Table 2 shows the detailed results of the four-step procedure testing for mediation effects. Model 1 indicated that student perceptions of both atmospheric phenomena were statistically significantly related to their academic engagement (yellow dust: $\mathrm{B}=0.405, \mathrm{p}<0.05$; monsoon: $\mathrm{B}=0.503, \mathrm{p}<0.01$ ) such that the more severe that they perceived the intensity of yellow dust or greater that they perceived the volume of rain, the less that they engaged with studying at school. Open communication in the parent-student relationship was positively related to students' academic engagement. However, only student perception of the intensity of yellow dust positively influenced students' concerns about their health, which is indicated by Model $2(\mathrm{~B}=1.285, \mathrm{p}<0.05)$. Problematic parent-student communication was positively correlated with students' concerns about their health. Model 3 also showed that students' concerns about their health negatively affected academic engagement $(B=0.051, p<$ 0.01 ). Open parent-student communication was positively correlated with academic engagement. Model 4 finally showed the relationship between student perception of the intensity of yellow dust and academic engagement at school became statistically insignificant when the variable of students' concerns about their health was controlled. This result indicated the full mediating effect of students' health concern between the independent and dependent variables. Although there seemed to be a statistically significant relationship between student perception of volume of rain and academic engagement [monsoon $(B=0.436$,

Table 2. Logistic regression results of testing for mediation effect.

\begin{tabular}{|c|c|c|c|c|c|c|c|c|}
\hline \multirow[t]{2}{*}{ Variable } & \multicolumn{2}{|c|}{$\begin{array}{c}\text { Model } 1 \\
\text { (atmosphere } \rightarrow \\
\text { academic engagement) }\end{array}$} & \multicolumn{2}{|c|}{$\begin{array}{c}\text { Model } 2 \\
\text { (atmosphere } \rightarrow \\
\text { health concern) }\end{array}$} & \multicolumn{2}{|c|}{$\begin{array}{c}\text { Model } 3 \\
\text { (health concerns } \rightarrow \\
\text { academic engagement) }\end{array}$} & \multicolumn{2}{|c|}{$\begin{array}{c}\text { Model } 4 \\
\text { (atmosphere, health } \\
\text { concerns } \rightarrow \text { academic } \\
\text { engagement) }\end{array}$} \\
\hline & B & $\operatorname{Exp}(B)$ & B & $\beta$ & B & $\operatorname{Exp}(B)$ & B & $\operatorname{Exp}(B)$ \\
\hline (Constant) & 0.548 & 1.730 & $25.412^{\star \star \star}$ & & 2.053 & 7.794 & 1.601 & 4.956 \\
\hline Yellow dust intensity & $0.405^{\star}$ & 0.667 & $1.285^{\star}$ & 0.118 & & & -0.313 & 0.732 \\
\hline $\begin{array}{l}\text { Amount of rainfall } \\
\text { (monsoon) }\end{array}$ & $0.503^{\star *}$ & 1.654 & -0.611 & -0.066 & & & $0.436^{*}$ & 1.547 \\
\hline $\begin{array}{l}\text { Parents-students: } \\
\text { Open comm. }\end{array}$ & $-0.376^{\star *}$ & 0.686 & 0.166 & 0.024 & $-0.325^{\star}$ & 0.722 & $-0.352^{\star}$ & 0.703 \\
\hline $\begin{array}{l}\text { Parents-students: } \\
\text { Problematic comm. }\end{array}$ & -0.029 & 0.972 & $1.686^{\star * *}$ & 0.235 & 0.096 & 1.100 & 0.052 & 1.054 \\
\hline \multirow[t]{3}{*}{$\begin{array}{l}\text { Students' concerns } \\
\text { about their health }\end{array}$} & & & & & $0.051^{* *}$ & 0.951 & $0.046^{*}$ & 0.955 \\
\hline & \multicolumn{2}{|c|}{$d f=4$} & & & \multicolumn{2}{|c|}{$d f=3$} & \multicolumn{2}{|c|}{$d f=5$} \\
\hline & $\begin{array}{r}-2 \text { Log likel } \\
\mathrm{X}^{2}= \\
\text { Cox \& Sr } \\
\text { Overall Per }\end{array}$ & $\begin{array}{l}d=337.042 \\
52^{* * *} \\
2^{2}=0.070 \\
\text { age }=77.0 \%\end{array}$ & $\begin{array}{r}\mathrm{F}= \\
\mathrm{R}^{2}= \\
\text { Adj. } \mathrm{F}\end{array}$ & $\begin{array}{l}75 \\
64 \\
.053\end{array}$ & $\begin{array}{r}-2 \text { Log likel } \\
\mathrm{X}^{2}= \\
\text { Cox \& } \mathrm{S} \\
\text { Overall Per }\end{array}$ & $\begin{array}{l}=332.188 \\
9^{\star * *} \\
2=0.055 \\
g e=76.9 \%\end{array}$ & $\begin{array}{c}\text { Cox \& Snell } \mathrm{R}^{2}=0.080 \\
\text { Overall Percentage }=76.2 \%\end{array}$ & $\begin{array}{l}d=323.631 \\
76^{\star * *} \\
2^{2}=0.080 \\
\text { age }=76.2 \%\end{array}$ \\
\hline
\end{tabular}

Note: Academic engagement $(0=$ high; $1=$ low $) .{ }^{*} \mathrm{p}<0.05,{ }^{* *} \mathrm{p}<0.01,{ }^{* * *} \mathrm{p}<0.001$. 
$\mathrm{p}<0.05)$ ], mediation effect of students' health concerns about their health was irrelevant; there was no statistically significant relationship between the amount of rainfall and students' concerns, which has already been examined by Model 2 . These results indicated that the more severe students perceived yellow dust to be, the more concerned they became about their health, which in turn reduced their academic engagement at school.

Additionally, this study examined the mediation effect of students' concerns about their health by using bootstrapped confidence intervals. Controlling for open and problematic parent-student communication, 5000 sample mediation effects were applied. As shown in Table 3, lower to upper limit of the bootstrapped confidence intervals were -0.161 to -0.008 at a $95 \%$ confidence level. Given that the confidence interval between the Lower Limit (LL) and the Upper Limit (UL) did not include 0 , the mediation effect was determined to be significant [29]. Testing for mediation effects using bootstrapping also proved that atmospheric conditions were likely to increase students' concerns about their health and thereby reduce their academic engagement at school.

\section{Conclusions}

Too often, we are unaware of the magnitude of the atmosphere's influence on our day-to-day lives and on Earth's ecosystem as a whole. Although previous studies have been conducted on these cause-and-effect relationships, the effect that the atmosphere has on students' lives in South Korea has been overlooked. Thus, this study examined how atmospheric phenomena particularly affected South Korean students' academic engagement at school. Responses to questionnaires from 345 middle and high school students in Seoul, South Korea were included in this study's final analysis.

In order to investigate the mediating effects of students' concern about their health on atmospheric conditions and school engagement, this study conducted Baron and Kenny's four-step regression analysis procedure and a bootstrap analysis. The results showed that both the perceived intensity of yellow dust and the perceived amount of rain negatively affected the students' academic engagement at school. However, the variable of students' concerns about their health was shown to completely mediate the relationship between perceived levels of yellow dust and academic engagement. No such mediating effect was shown on the relationship between the perceived amount of rain and academic engagement.

Table 3. Mediation effect as measured by bootstrapping.

\begin{tabular}{ccccc}
\hline & & \multicolumn{2}{c}{ Bootstrap } \\
\cline { 3 - 4 } Mediator & Coefficient & S.E. & \multicolumn{2}{c}{ Confidence interval (95\%) } \\
\cline { 3 - 4 } & & & Boot LLCI & Boot ULCI \\
\hline Indirect effect & -0.059 & 0.038 & -0.161 & -0.008 \\
\hline
\end{tabular}

Note: LLCI = Lower Level (2.5th percentile) Confidence Interval; ULCI = Upper Level (97.5th percentile) Confidence Interval. 
There are a number of policy suggestions to improve students' academic engagement that can be made based on the findings of this study. First, the amount of yellow dust during the spring should be reduced by preventing desertification in southern Mongolia and northern China. Although China has begun to combat desertification by planting forests, Mongolia has struggled to do so because of a lack of funds [30]. A great deal of this yellow dust ultimately descends upon the Korean peninsula, so the Korean government should cooperate with other countries to assist in preventing desertification, perhaps in the form of providing economic aid to Mongolia. In order to reduce the damage caused by heavy rainfall during the monsoon, the government should forecast the amount of precipitation as accurately as possible, repair embankments and walls to prevent landslides, and improve sewer systems to more effectively deal with floods.

Second, school authorities should recognize the seriousness of the impact that yellow dust and heavy rainfall have on students' academic engagement at school. Yellow dust can impact students' concerns regarding their health and academic engagement at the same time. Thus, schools should provide air purifiers to reduce students' concerns about their health and practical education, training, and manuals for teachers on how to respond to yellow dust.

This study was the first on the effect of atmospheric phenomena on students' academic engagement at school, but it had some limitations. The subjects surveyed in this study were only from Seoul, so national or international populations must be studied to generalize the results of this study. This study also did not control for various variables, such as school facilities, that might affect students' academic engagement. Thus, future studies must overcome these limitations to better understand how atmospheric phenomena affect students' lives at school.

\section{References}

[1] Chu, J. (2013) Study: Air Pollution Causes 200,000 Early Deaths Each Year in the US: New MIT Study Finds Vehicle Emissions Are the Biggest Contributor to These Premature Deaths. MIT News.

http://news.mit.edu/2013/study-air-pollution-causes-200000-early-deaths-each-year -in-the-us-0829

[2] The World Bank (2016) Air Pollution Deaths Cost Global Economy US\$225 Billion. The World Bank News.

http://www.worldbank.org/en/news/press-release/2016/09/08/air-pollution-deathscost-global-economy-225-billion

[3] Bak, S.H. (2018) Talks Continue on "Alternate No-Driving Day" to Fight Dust. The Korea Herald. http://www.koreaherald.com/view.php?ud=20180118000899\&ACE_SEARCH=1

[4] Ladouceur, A. (2013) A Korean Spring: The Beautiful and the Ugly. Korea4expats.com News. http://www.korea4expats.com/news-yellow-spring-korea.html

[5] Ministry of Public Administration and Security (2014) Annual Disaster Report. Sejong City. 
[6] An, J.H., Lim, C.H., Jung, S.H., Kim, A.R. and Lee, C.S. (2016) Effects of Climate Change on Biodiversity and Measures for Them. Journal of Wetlands Research, 18, 474-480. https://doi.org/10.17663/JWR.2016.18.4.474

[7] Eom, K.H., Kim, H.S., Han, I.S. and Kim, D.H. (2015) An Analysis of Changes in Catch Amount of Offshore and Coastal Fisheries by Climate Change in Korea. The Journal of Fisheries Business Administration, 46, 31-41. https://doi.org/10.12939/FBA.2015.46.2.031

[8] Lee, G.S. (2014) Effects of Climate Change on the Crops Growing Environment. M.Sc. Thesis, Chonnam National University, Yeosu, Unpublished.

[9] Oh, H. (2015) Measuring the Weather Risk in Manufacturing and Service Sectors in Korea. Environmental and Resource Economics Review, 24, 551-572. https://doi.org/10.15266/KEREA.2015.24.3.551

[10] Korea Meteorological Administration (2009) Climate of Korea. http://web.kma.go.kr/eng/biz/climate_01.jsp

[11] Uyeda, H., Jou, B.J. and Lee, D. (2017) Recent Development of Heavy Rain Research Associated with Summer Monsoon in East Asia Excited by Advances in Weather Radar. In: Chang, C., Kuo, H., Lau, N., Johnson, R.H., Wang, B. and Wheeler, M.C., Eds., The Global Monsoon System: Research and Forecast, World Scientific Publishing, Danvers, MA, 227-243. https://doi.org/10.1142/9789813200913_0018

[12] Ministry of Public Administration and Security (2014) Annual Disaster Report. Sejong City.

[13] Ban, G.S. (2013) Jangma. http://terms.naver.com/entry.nhn?docId=3576687\&cid=58947\&categoryId=58981

[14] Volodzko, D.J. (2017) China Is to Blame for Korea's Pollution? Really? South China Morning Post.

http://www.scmp.com/week-asia/politics/article/2087447/china-blame-koreas-pollu tion-really

[15] (2015) Yellow Sand-Dust, Hwangsa. http://www.korea4expats.com/article-yellow-dust-korea.html

[16] Yeo, S.M. (2017) Chinese Hwangsa's Causes, Damages, and Future Management. https://blog.naver.com/cnsisa9582/221039556875

[17] Schaufeli, W.B. and Bakker, A.B. (2004) Utrecht Work Engagement Scale: Preliminary Manual.

http://www.wilmarschaufeli.nl/publications/Schaufeli/Test\%20Manuals/Test_manu al_UWES_English.pdf

[18] Choo, H.T. and Sohn, W.S. (2012) Validating the Korean Version of the Utretch Work Engagement Scale-Student (UWES-S). Journal of Education Evaluation, 24, 897-920.

[19] Shin, H.K. and Won, H. (1997) A Study on the Development of the Korean Alexithymia Scale. Korean Journal of Clinical Psychology, 16, 219-231.

[20] Cohen, S., Kamarck, T. and Mermelstein, R. (1983) A Global Measure of Perceived Stress. Journal of Health and Social Behavior, 24, 385-396. https://doi.org/10.2307/2136404

[21] Park, J. and Seo, Y.S. (2010) Validation of the Perceived Stress Scale (PSS) on Samples of Korean University Students. Korean Journal of Psychology: General, 29, 611-629.

[22] Fan, W. and Williams, C.M. (2010) The Effects of Parental Involvement on Students' Academic Self-Efficacy, Engagement and Intrinsic Motivation. Educational 
Psychology, 30, 53-74. https://doi.org/10.1080/01443410903353302

[23] Kim, N.H. and Lee, J. (2013) The Relationship between Perceived Parent-Adolescent Relationship and the Middle School Students' Learning Flow: The Mediating Effects of Self-Determinated Motivation. The Korea Journal of Youth Counseling, 21, 211-231.

[24] Park, Y.S., Lee, Y.S., Lee, S.H. and Kim, T.O. (2015) The Effects of Parent-Child Relationship and Self-Efficacy on Adolescent Academic Achievement and Filial Piety. The Korean Journal of Educational Psychology, 29, 505-542. https://doi.org/10.17286/KJEP.2015.29.3.06

[25] Kim, J.H. (2004) Parent-Adolescent Communication and the Stress and Stress Coping Style of Middle School Student. M.Sc. Thesis, Kookmin University, Seoul, Unpublished.

[26] Barnes, H.L. and Olson, D.H. (1982) Parent-Adolescent Communication Scale. In: Olson, D.H., McCubbin, H.I., Barnes, H., Larsen, A., Muxen, M. and Wilson, M., Eds., Family Inventories: Inventories Used in a National Survey of Families across the Family Life Cycle, Family Social Science, University of Minnesota, Saint Paul, MN, 33-48.

[27] Dormann, C.F., Elith, J., Bacher, S., Buchmann, C., Carl, G., Carré, G., Marquéz, J. R.G., Gruber, B., Lafourcade, B., Leitão, P.J., Münkemüller, T., McClean, C., Osborne, P.E., Reineking, B., Schröder, B., Skidmore, A.K., Zurell, D. and Lautenbach, S. (2013) Collinearity: A Review of Methods to Deal with It and a Simulation Study Evaluating Their Performance. Ecography, 36, 27-46. https://doi.org/10.1111/j.1600-0587.2012.07348.x

[28] Baron, R.M. and Kenny, D.A. (1986) The Moderator-Mediator Variable Distinction in Social Psychological Research: Conceptual, Strategic, and Statistical Considerations. Journal of Personality and Social Psychology, 51, 1173-1182. https://doi.org/10.1037/0022-3514.51.6.1173

[29] Shrout, P.E. and Bolger, N. (2002) Mediation in Experimental and Nonexperimental Studies: New Procedures and Recommendations. Psychological Methods, 7, 422-445. https://doi.org/10.1037/1082-989X.7.4.422

[30] (2015) Steps against Yellow Dust. The Korean Times. http://www.koreatimes.co.kr/www/news/opinon/2016/01/202_174065.html 